\title{
Anti-oxidative effect of resveratrol on aluminum induced toxicity in rat cerebral tissue
}

\author{
Zakaria $\mathrm{MMH}^{1}$, Hajipour $\mathrm{B}^{2}$, Estakhri $\mathrm{R}^{3}$, Saleh $\mathrm{BM}^{4}$ \\ Department of Neurology, Tabriz Branch, Islamic Azad University, Tabriz, Iran. \\ Hajipourb@yahoo.com
}

\begin{abstract}
INTRODUCTION: The direct protective effects of resveratrol against oxidative stress have been demonstrated in neuroglial cells, the mechanisms of these effects are not fully understood. The aim of this research was to study the effect of resveratrol on AL induced cerebral injury in rat.

METHODS: We divided the groups as follows with 10 animals each: a) Group I - served as control receiving normal drinking water and diet ad libitum. b) Group II - animals were administered aluminum at a dose level of $100 \mathrm{mg} / \mathrm{kg}$ body weight for a period of 6 weeks daily through oral gavage. c) Group III - animals were administered aluminum at a dose level of $100 \mathrm{mg} / \mathrm{kg}$ body weight and resveratrol at a dose of $10 \mathrm{mg} / \mathrm{kg}$ body weight intraperitoneally for a period of 6 weeks daily. After 6 weeks rats were anesthetized and decapitated. Brains were removed immediately and frozen in liquid nitrogen

RESULTS: The levels of SOD and GPx antioxidant enzymes were decreased in all of the groups receiving aluminium, but it was less severe in resveratrol treated group. SOD and GPx levels in aluminium + resveratrol group were higher than in the aluminum group $(p<0.05)$. MDA level, as an index of lipid peroxidation, increased significantly in all of the groups receiving aluminium. MDA level was lower in aluminium + resveratrol group compared to aluminum group and the difference was significant $(p<0.05)$.

CONCLUSIONS: This study suggests that resveratrol is effective in preventing AL induced toxicity by reducing MDA production in cerebral tissue. Resveratrol also attenuated SOD and GPx suppression in cerebral tissue significantly. Our findings provide the rationale for further studies directed to understanding the mechanism of resveratrol in preventing neurodeterioration (Tab. 1, Ref. 35). Text in PDF www.elis.sk.

KEY WORDS: aluminum, brain, resveratrol.
\end{abstract}

\section{Introduction}

There is an increasing evidence in the literature that during environmental stress reactive oxygen species (ROS) can cumulatively damage biological molecules, leading to structural and functional deterioration of cells during the aging process (1).

Aluminium (Al) is the third most abundant element on the earth crust and gets an easy access to our body through use of cooking utensils, deodorants, antacids, etc. Al is routinely used as a water treatment reagent and is often added in the processing of food and pharmaceutical products (antacids) (2). Although aluminum (Al) is a relatively low redox mineral, it can induce oxidative damage through multiple mechanisms. It can bind to negatively charged brain phospholipids, which contain polyunsaturated fatty acids and are easily attacked by reactive oxygen species (ROS) such as $\mathrm{O}_{2}{ }^{--}, \mathrm{H}_{2} \mathrm{O}_{2}, \mathrm{OH}^{\cdot}$, and $\mathrm{OH}^{-}(3)$. Aluminum can also stimulate iron-

${ }^{1}$ Department of Neurology, Tabriz Branch, Islamic Azad University, Tabriz, Iran, ${ }^{2}$ Department of Surgery, Urmia University of Medical Sciences, Urmia, Iran, ${ }^{3}$ Department of Pathology, Tabriz University of Medical Sciences, Tabriz, Iran, and ${ }^{4}$ Tabriz Branch, Islamic Azad University, Tabriz, Iran

Address for correspondence: B. Hajipour, Department of Surgery, Urmia University of Medical Sciences, Urmia, Iran.

Acknowledgments: This work was supported by a grant from Tabriz Branch, Islamic Azad University, Tabriz (Iran). initiated lipid peroxidation in the Fenton reaction, which causes ROS production and $\mathrm{Fe}^{3+}$ formation. Superoxide $\left(\mathrm{O}_{2}{ }^{-}\right)$is neutralized by $\mathrm{Al}^{3+}$ to form an $\mathrm{Al}-\mathrm{O}_{2}{ }^{-}{ }^{-}$complex, which increases the oxidative capacity of $\mathrm{O}_{2}{ }^{-}{ }^{-}$(4). Aluminium has been reported to alter blood-brain barrier (5) and gets deposited in the cortex, cingulat bundles, corpus callosum (6) and hippocampus. (7) Aluminium being an inert metal has been suggested to induce oxidative damage indirectly by potentiating the peroxidative effect of $\mathrm{Fe}^{2+}(8)$. AL generates reactive oxygen species, resulting in oxidative deterioration of lipids, proteins and DNA. Therefore, the estimation of free radical generation and antioxidant defense has become an important aspect of investigation in mammals (9).

Resveratrol (trans-3,49,-5-trihydroxystilebene), a natural phytoalexin compound found in various plants such as grapes and berries, is known to have potent anti-oxidant and anti-tumorigenic activities (10). Many studies have shown that resveratrol can prevent or slow the progression of a variety of conditions, including cancers, cardiovascular diseases, or ischemic injuries and can enhance stress resistance and extend lifespan (11). Resveratrol also promotes antioxidant defense by regulating a host of antioxidant enzymes (12). Moreover, it has been demonstrated that resveratrol has beneficial effects in neurological diseases (13) and is able to inhibit amyloid peptide neurotoxicity (14). Whilst direct protective effects of resveratrol against oxidative stress have been demon- 


\section{9-272}

strated in neuroglial cells, the mechanisms of these effects are not fully understood (14). The aim of this research was to study the effect of resveratrol on AL induced cerebral injury in rat.

\section{Materials and methods}

Healthy male Wistar rats were purchased from central animal house of pastor. The animals were acclimatized in the departmental animal house for 2 weeks in plastic cages and were provided feed and water ad libitum. The rats were monitored for their health and body weight. The animals were kept and cared for and during all stages in compliance with the applicable guidelines and regulations of the institute. We divided the groups as follows with 10 animals each:

(a) Group I - served as control receiving normal drinking water and diet ad libitum.

(b) Group II - animals were administered aluminum at a dose of $100 \mathrm{mg} / \mathrm{kg}$ body weight for a period of 6 weeks daily through oral gavage (15).

(c) Group III - animals were administered aluminum at a dose of $100 \mathrm{mg} / \mathrm{kg}$ body weight and resveratrol at a dose of $10 \mathrm{mg} / \mathrm{kg}$ body weight intraperitoneally for a period of 6 weeks daily (16). After 6 weeks rats were anesthetized and decapitated. Brains were removed immediately and frozen in liquid nitrogen.

\section{Assay of antioxidant enzymes}

The cerebral tissue was frozen in liquid nitrogen and stored at $-80{ }^{\circ} \mathrm{C}$ until further preparation. In order to measure anti-oxidant enzyme activity, the cerebral samples were homogenized in $1.15 \%$ $\mathrm{KCl}$ solution. Superoxide dismutase ( $\mathrm{SOD}$ ) activity in liver tissue was determined by using xanthine and xanthine oxidase to generate superoxide radicals which then react with 2-(4-iodophenyl)-3-(4nitrophenol)-5-phenyltetrazolium chloride to form a red formazan dye. The SOD activity was then measured by the degree of inhibition of this reaction (Ransod, Randox Laboratories Ltd., Antrim, United Kingdom). Results were obtained as SOD Unit/ mg protein (17).

Glutathione peroxidase (GPx) activity in cerebral tissue was measured using the method described by Paglia and Valentine. GPx catalyses the oxidation of glutathione by cumene hydroperoxide. In the presence of glutathione reductase and NADPH, the oxidized glutathione is immediately converted to reduced form with a concomitant oxidation of NADPH to $\mathrm{NADP}^{+}$. The decrease in absorbance at $340 \mathrm{~nm}$ is measured (Ransod, Randox Laboratories Ltd., Antrim, UK). Results were obtained as GPx Unit/mg protein (18).

\section{Tissue MDA level}

Tissue malondialdehyde was determined by the method of Uchiyama and Mihara (19). 3-mL aliquot of $1 \%$ phosphoric acid and $1 \mathrm{~mL}$ of $0.6 \%$ thiobarbituric acid solution were added to 0.5 $\mathrm{mL}$ of $10 \%$ tissue homogenate. The mixture was heated in boiling water for 45 minutes. After cooling, the color was extracted into 4 $\mathrm{mL}$ of n-butanol. The absorbance was measured in a spectrophotometer (Amersham Pharmacia Biotech UK Ltd., Little Chalfont, Buckinghamshire, UK) at $532 \mathrm{~nm}\left(\dot{\varepsilon}=.56 \times 10^{5} \mathrm{~mol} / \mathrm{L}^{-1} \mathrm{~cm}^{-1}\right)$. The
Tab. 1. The effect of resveratrol on antioxidant enzymes content and MDA levels in rat cerebral tissue.

\begin{tabular}{lccc}
\hline & Control & Aluminum & $\begin{array}{c}\text { Aluminum+ } \\
\text { Resveratrol }\end{array}$ \\
\hline Cerebral GPx & $5.07 \pm .49$ & $3.18 \pm 0.51$ & $3.7700 \pm 0.26$ \\
Cerebral SOD & $4.41 \pm .78$ & $3.02 \pm 0.22$ & $3.7700 \pm 0.49$ \\
Cerebral MDA & $4.03 \pm .65$ & $6.83 \pm 0.71$ & $4.9300 \pm 0.52$ \\
\hline
\end{tabular}

The values are shown as mean \pm SD for rats in each group and difference of ( $\mathrm{p}<$ 0.05 ) considered significant. SOD - superoxide dismutase, GPx - glutathione peroxidase, MDA - malondialdehyde

amounts of lipid peroxides calculated as thiobarbituric acid reactive substances (TBARS) of lipid peroxidation were expressed as $\mathrm{nMol} / \mathrm{ml}(20)$.

\section{Statistical analysis}

Data were expressed as means $\pm \mathrm{SD}$. Differences among various groups were tested for statistical significance using the one-way ANOVA test and Tukeys post test. A p value of less than 0.05 denoted the presence of a statistically significant difference.

\section{Results}

\section{SOD and GPx level}

The levels of SOD and GPx antioxidant enzymes were decreased in all of the groups receiving aluminium, but it was less severe in resveratrol treated group. SOD and GPx levels in aluminium + resveratrol group were higher than in the aluminum group $(\mathrm{p}<0.05)$ (Tab. 1).

\section{MDA level}

MDA level, as an index of lipid peroxidation, increased significantly in all of the groups receiving aluminium. MDA level was lower in aluminium + resveratrol group compared to aluminum group and significantly $(\mathrm{p}<0.05)$.

\section{Discussion}

Oxidative stress is associated with an increase in oxidizing species that destruct the vascular and neuronal cells in central nervous system. Oxidative stress is due to the imbalance between the oxygen free radicals generated and the antioxidant defense system to detoxify the reactive intermediates (21). Oxidative stress changes the signaling pathways that may induce cellular responses such as inflammation, cell proliferation, and cell survival and death (22). Reactive oxygen species (ROS) are chemically reactive molecules that consist of oxygen ions and peroxides that include hydrogen peroxide, singlet oxygen, nitric oxide, peroxynitrite, and superoxide free radicals. The release of peroxides and free radicals is toxic to the cell, which may lead to cell death. The antioxidant enzymes, such as superoxide dismutase (SOD), catalase, and peroxidases, and non-enzymatic free radical scavengers (ascorbic acid, $\alpha$-tocopherol, and GSH) convert the reactive oxygen species to water and oxygen, the stable molecules. These antioxidants are known to protect the cells and tissues against oxidative injury caused by reactive oxygen species (23). 
Superoxide dismutase (SOD), an oxygen radical scavenger, which converts the superoxide anion radical present in the upper stream of reactive oxygen metabolism cascade, will afford protection from cell damage (24). SOD catalyzes the dismutation of the superoxide anion $\left(\mathrm{O}_{2}^{-}\right)$into $\mathrm{H}_{2} \mathrm{O}$; GSH-Px is a selenoprotein, which reduces lipidic or nonlipidic hydroperoxides as well as $\mathrm{H}_{2} \mathrm{O}_{2}$ while oxidizing $\mathrm{GSH}$ (25). In our study, treatment with $\mathrm{AlCl} 3$ caused a significant increase in brain MDA and decrease in cerebral GPx and SOD activities (Tab. 1). Similarly El-Demerdash (26) reported that the lipid peroxidation significantly increased during $\mathrm{Al}$ exposure and this was used as a marker of $\mathrm{Al}$ toxicity. On the other hand, Nayak et al (27) found that $\mathrm{AlCl} 3$ caused a significant decrease in the levels of GPx and SOD, indicating that $\mathrm{Al}$ decreases antioxidant defense system. In our study resveratrol administration decreased MDA elevation in rats receiving both $\mathrm{AL}$ and resveratrol. Resveratrol also attenuated SOD and GPx suppression by AL administration significantly.

Both Jutka and Gill (28), and Gupta and Shukla (29) observed that al administration lowered SOD and GPX activities in the brains of rats. It is noteworthy that increased lipoperoxidation was also found by these authors in brain tissues. Similar results have been reported by Chainy et al (30) in the liver, and by Verstraeten et al (31) in the brain myelin of mice. Taken together, the preceding results suggest that $\mathrm{A}$ ( promotes oxidative stress by decreasing the activity of free radicals scavenging enzymes such as SOD and GPX, a biological effect confirmed by increased accumulation of lipoperoxidation products.

Moumen et al (32) reported that after Al administration GPX is decreased in brain tissue, but they found increased SOD activity in brain tissue when most authors report opposite results in a similar setting. They had already found a similar change in the plasma of SALS patients (33) (increased SOD and decreased GPX activities), while RBC SOD activity is unchanged in these patients (34). It was then suggested that, at least in plasma, this increase reflected predominantly Ec SOD (35). Such an interpretation is difficult to apply to the brain, unless the extraction method chosen here would artificially enhance Ec SOD extraction. A more appealing explanation could be that $\mathrm{AL}$ administration induces a biphasic response in SOD, a more appealing explanation could be that $\mathrm{AL}$ administration induces a biphasic response in SOD with an initial enhancement of activity followed by a decrease. The duration of administration was shorter in Moumen et al (32) study (1 week) than in that of Jutka and Gill (28) (2 weeks) and that of Gupta and Shukla (10) (29 months).

\section{Conclusions}

This study suggests that resveratrol is effective in preventing AL induced toxicity by reducing MDA production in cerebral tissue. Resveratrol also attenuated SOD and GPx suppression in cerebral tissue significantly. Our findings provide the rationale for further studies directed in understanding of mechanism of resveratrol in preventing neurodeterioration.

\section{References}

1. Sohal RS, Mockett RJ, Orr WC. Current issues concerning the role of oxidative stress in aging: a perspective. Results Probl Cell Differ 2000; 29: 45-66.

2. Yokel RA. The toxicology of aluminum in the brain: a review. Neurotoxicology 2000; 21: 813-828.

3. Verstraeten SV, Nogueira LV, Schreier S, Oteiza PI. Effect of trivalent metal ions on phase separation and membrane lipid packing: role in lipid peroxidation. Arch Biochem Biophys 1997; 338 (1): 121-127.

4. Exley C. The pro-oxidant activity of aluminum. Free Radic Biol Med 2004; 36 (3): 380-387.

5. Zatta P, Ibn-Lkhayat-Idrissi M, Zambenedetti P, Kilyen M, Kiss T. In vivo and in vitro effects of aluminum on the activity of mouse brain acetylcholinesterase. Brain Res Bull 2002; 59: 41-45.

6. Platt B, Fiddler G, Riedel G, Henderson Z. Aluminum toxicity in the rat brain: histochemical and immunocytochemical evidences. Brain Res Bull 2001; 55: 257-267.

7. Struys-Ponsar C, Kerkhofs A, Gauthier A, Soffie M, Van den Bosch de Aguilar P. Effects of aluminum exposure on behavioural parameters in the rat. Pharmacol Biochem Behav 1997; 56: 643-648.

8. Golub MS, Han B, Keen CL. Aluminum uptake and effects on transferrin mediated iron uptake in primary cultures of rat neurons, astrocytes and oligodendrocytes. Neurotoxicology 1999; 20 (6): 961-970.

9. Strong MJ, Garruto RM, Joshi JG, Mundy WR, Shafer TJ. Can the mechanisms of aluminum neurotoxicity be integrated into a unified scheme? J Toxicol Environ Health 1996; 48 (6): 599-613.

10. Vang O, Ahmad N, Baile CA, Baur JA, Brown $K$ et al. What is new for an old molecule? Systematic review and recommendations on the use of resveratrol. PLoS One 2011; 6: e19881.

11. Brasnyó PL, Molnár GA, Mohás M, Markó L, Laczy B, Cseh J, Mikolás E, Szijártó IA, Mérei A, Halmai R et al. Resveratrol improves insulin sensitivity, reduces oxidative stress and activates the Akt pathway in type 2 diabetic patients. Br J Nutr 2011; 106: 383-389.

12. Robb EL, Page MM, Wiens BE, Stuart JA. Molecular mechanisms of oxidative stress resistance induced by resveratrol: specific and progressive induction of MnSOD. Biochem Biophys Res Commun 2008; 367: 406-412.

13. Quincozes-Santos A, Gottfried C. Resveratrol modulates astroglial functions: neuroprotective hypothesis. Ann NY Acad Sci 2011; 1215 : $72-78$.

14. Richard T, Pawlus AD, Iglesias ML, Pedrot E, Waffo-Teguo P et al. Neuroprotective properties of resveratrol and derivatives. Ann NY Acad Sci 2011; 1215: 103-108.

15. Nehru B, Bhalla P, Garg A. Further evidence of centrophenoxine mediated protection in aluminium exposed rats by biochemical and light microscopy analysis. Food Chem Toxicol 2007; 45 (12): 2499-2505.

16. Yar AS, Menevse S, Alp E, Helvacioglu F, Take G. The effects of resveratrol on cyclooxygenase-1 and cyclooxygenase-2 mRNA and protein levels in diabetic rat kidneys. Mol Biol Rep 2010; 37 (5): 2323-2331.

17. Paoletti F, Aldinucci D, Mocali A, Caparrini A. A sensitive spectrophotometric method for the determination of superoxide dismutase activity in tissue extracts. Anal Biochem 1986; 154: 536-541.

18. Paglia DE, Valentine WN. Studies on the quantitative and qualitative characterization of erythrocyte glutathione peroxidase. J Lab Clin Med 1967; 70: 158-169. 


\section{9-272}

19. Mihara M, Uchiyama M. Effects of antioxidants on the TBA reaction of various rat liver homogenates. Biochem Med 1983; 30: 131.

20. Kirimlioglu H, Ecevit A, Yilmaz S, Kirimlioglu V, Karabulut AB. Effect of resveratrol and melatonin on oxidative stress enzymes, regeneration, and hepatocyte ultrastructure in rats subjected to $70 \%$ partial hepatectomy. Transplant Proc 2008; 40: 285-289.

21. Balaban RS, Nemoto S, Finkel T. Mitochondria, oxidants, and aging. Cell 2005; 120: 483-495.

22. Kregel KC, Zhang HJ. An integrated view of oxidative stress in aging: basicmechanisms, functional effects, and pathological considerations. Amer J Physiol 2007; 292: 18-36.

23. Uttara B, Singh AV, Zamboni P, Mahajan RT. Oxidative stress and neurodegenerative diseases: a review of upstream and downstream antioxidant therapeutic options. Curr Neuropharmacol 2009; 7: 65-74.

24. Minor T, Isselhard W, Yamamoto Y, Obara M, Saad S. The effects of allopurinol and SOD on lipid peroxidation and energy metabolism in the liver after ischemia in an aerobic/anaerobic persufflation. Surg Today 1993; $23: 728$.

25. Michiels C, Raes M, Toussaint O, Remacle J. Importance of Seglutathione peroxidase, catalase, and $\mathrm{Cu} / \mathrm{Zn}-\mathrm{SOD}$ for cell survival against oxidative stress. Free Radic Biol Med 1994; 17: 235-248.

26. El-Demerdash FM. Antioxidant effect of vitamin E and selenium on lipid peroxidation, enzyme activities and biochemical parameters in rats exposed to aluminium. J Trace Elem Med Biol 2004; 18 (1): 113-121.

27. Nayak P, Sharma SB, Chowdary NV. Thalamic superoxide and peroxide handling capacity (SPHC): An experimental study with aluminum, ethanol and tocopherol in rats. Indian J Exp Biol 2015; 53 (9): 568-573.
28. Jutka D, Gill KD. Effect of aluminum on regional brain antioxidant defense status in wistar rats. Res Exp Med 1996; 196: 187-194.

29. Gupta A, Shukla GS. Effect of aluminum exposure on the Level of conjugated dienes and enzymatic antioxidants in hippocampus and whole brain of rat. Bull. Environ. Contam Toxicol 1995; 55: 716-722.

30. Chainy GBN, Samanta L, Rout NB. Effect of aluminum on superoxide dismutase, catalase and lipoperoxidation of rat liver. Res Commun Mot Path Pharmacol 1996; 94: 217-220.

31. Verstraeten SV, Golub MS, Keen CL, Oteiza, PL. Myelin is a preferential target of aluminum-mediated oxidative damage. Arch Biochem Biophyh 1997; 344 (2): 289-294.

32. Moumen R, Ait-Oukhatar N, Bureau F, Fleury C, Bouglé D, Arhan P, Neuville D, Viader F. Aluminium increases xanthine oxidase activity and disturbs antioxidant status in the rat. J Trace Elem Med Biol 2001; 15 (2-3): 89-93.

33. Moumen R, Nouvelot A, Duval D, Lechevalier B, Viader F. Plasma superoxide dismutase and glutathione peroxidase activity in sporadic amyotrophic lateral sclerosis. J Neurol Sci 1997; 151: 35-39.

34. Przedborski S, Donaldson DM, Murphy PL, Hirsch O, Lange D, Naini AB, McKenna-Yasek D, Bown RH. Blood superoxide dismutase, catalase, and glutathione peroxidase activities in familial and sporadic amyotrophic lateral sclerosis. Neurodegeneration 1996; 5: 57-64.

35. Marklund SL, Holme E, Heffner L. Superoxide dismutase in extracellular fluids. Clin Chim Acta 1982; 126: 41.

Received December 28, 2016. Accepted January 16, 2017. 